\title{
Retired Australian's use of Information Technology: A Preliminary Study
}

\author{
Joanne Phythian \\ Southern Cross Business School, Southern Cross University \\ Hogbin Drive Coffs Harbour, NSW, 2450, Australia \\ Email: joanne.phythian@scu.edu.au \\ Julie Tucker \\ Office of Community Engagement, Southern Cross University \\ Hogbin Drive Coffs Harbour, NSW, 2450, Australia \\ Email: julie.tucker@scu.edu.au \\ Tim Comber \\ Southern Cross Business School, Southern Cross University \\ Hogbin Drive Coffs Harbour, NSW, 2450, Australia \\ Email: tim.comber@scu.edu.au \\ Bruce Armstrong \\ Southern Cross Business School, Southern Cross University \\ Hogbin Drive Coffs Harbour, NSW, 2450, Australia \\ Email: bruce.armstrong@scu.edu.au \\ Simon Pervan \\ Southern Cross Business School, Southern Cross University \\ Bilinga, Qld, 4225, Australia \\ Email: simon.pervan@scu.edu.au
}

\begin{abstract}
In July 2010, Coffs Harbour, Australia was announced as one of fourteen National Broadband Network (NBN) second release sites and in February 2013, a number of households and businesses in Coffs Harbour had infrastructure installed to enable them to access the NBN (www.minister.dbcde.gov.au). High speed internet and the new generation of internet-based services has the potential to provide better health outcomes, increased social connectedness, enhanced functional capability and caregiver support for those most likely to need these services ${ }^{1}$. A survey of technology use of residents of a retirement home on the Mid North Coast of NSW, Australia, showed a low uptake of technology and low engagement with online activities. An understanding of perceptions of technology usefulness, together with actual usage is necessary to assist in informing public policy and ensure that information, resources and programs aimed at increasing levels of internet uptake and use by older Australians is targeted, appropriate and effective.
\end{abstract}

Keywords: National Broadband Network; social inclusion; older Australians; internet usage

\section{Introduction}

The growth in the number of Australians aged over 60 years $^{2}$ and the rapid increase in the use and availability of technology $y^{3,4}$ would seem to indicate research is needed to examine the perceptions and attitudes of this group of Australians to technology use. Failure to look at technology use b y this group could lead to misconceptions relating to policy decisions associated 
with the NBN and with the types of programs needed to ensure all Australians realise the benefits.

\section{Review of Current Research}

The adoption and use of information technology is becoming an increasingly important part of everyday life ${ }^{4}$. With over $68 \%$ of internet users making a purchase online in 2010-2011 ${ }^{4}$, and broadband access in over 6.2 million Australia households ${ }^{4}$, understanding how aged Australians adapt and engage with online technologies becomes increasingly important.

As commercial service providers, public sector services and other providers increasingly move online, users should be provided with an understanding of their use and be conversant with the technologies needed for access. The researchers did surmise that older Australians and in particular residents of ret irement villages may not be utilising technology to maximise their standard of living.

The rate of broadband internet access in households increased from $64 \%$ in $2006-2007^{5}$ to $73 \%$ in $2010-$ $2011^{6}$. However, it is $\mathrm{n}$ ot clear whether the same increase is reflected across all household types, including residences in retirement villages, or is mainly evident in other household types in Australia.

The ABS Census data showed that among older Australians (those aged over 60 years) $54 \%$ had internet access at home in 2009, an increase from $29 \%$ in $2003^{6}$. General web browsing (86\%) a nd email/chat rooms $(82 \%)$ were the most common online activities for this age group ${ }^{6}$. Other online activities included accessing government websites (46\%) and online purchasing $(41 \%)^{6}$. Data from the ABS indicated $41 \%$ of older Australians "used the internet at any location" in 2009, which was an increase from $21 \%$ in $2003^{6}$.

Population statistics showed that at June 2012, people aged 65 years or over a ccounted for $14 \%$ of Australia's population ${ }^{7}$. This is expected to increase to between $23 \%$ and $25 \%$ in $2056^{5}$. As well, the increase in those Australians aged 85 years and over is projected to expand from $1.6 \%$ of the total population in 2007 , to between $4.9 \%$ and $7.3 \%$ in $2056^{5}$. Therefore, as Australians continue to live longer and healthier lives ${ }^{2}$ older Australians can benefit from information technology, which can provide greater independence and less reliance on others in the community, health benefits, lifestyle, support, and the ability to continue to engage in so ciety regardless of iss ues that become apparent with age, such as mobility.

Online information technologies can also assist older Australians wishing to remain in their own homes. The internet provides access to online shopping, medical services, communications utilities, social sites and community support services. While it is important to ensure that the use of technology does not reduc e contact with society it is equally important that older Australians are aware of the benefits of being online, particularly those with mobility issues.

Much of the research examining older people's use of technology has been conducted internationally. The studies have focussed on:

- the level of engagement with various technologies ${ }^{8,9,10}$,

- factors influencing engagement with information technology ${ }^{11,12,13}$,

- $\quad$ the IT skill levels of older adults ${ }^{14}$,

- comparisons between older and younger adults use of technology ${ }^{15,16}$,

- the perceived risks and benefits of online shopping by older adults ${ }^{17,18,19}$, and

- older adults attitudes about technology ${ }^{15,20}$.

Research on internet usage by older people within Australia has occurred through organisations such as the Australian Bureau of Statistics (ABS), the Australian Research Council Centre of Excellence for $\mathrm{C}$ reative Industries and Innovation (CCI), and the Australian Communications and Media Authority (ACMA). Additionally research has been conducted on internet shoppers in Australia and their buying behaviour ${ }^{21}$, older Australians and e-health ${ }^{22}$, and older Australians and technology usage $\mathrm{e}^{23}$. However, many of these studies focus on the number, type and fre quency of internet usage and there has been little research that concentrates specifically on older Australians and information technology use, uptake and adoption along with the factors impacting on older Australians online activities or if in fact they even engage 'online'.

There are relatively few studies on the elderly and technology use in MIS research ${ }^{31}$. Potential reasons for this include MIS research having an organisational focus, and with elderly people not employed they are not included, and the potential assumption that older people do not buy a great deal and do not engage in technology as much as other age groups ${ }^{31}$.

So while there is considerable research focussed on internet and technology usage, there is little research 
that has specifically examined internet and technology use among retired Australians in a regional context. The rollout of the NBN throughout regional areas and in particular the Coffs Harbour area, presents an ideal location to examine uptake among a key sector of the community likely to receive significant benefits from communications technologies that could be enabled via the NBN.

Thus the research aimed to address the following questions:

- What information and communications technologies do older Australians use?

- How are older Australians using information and communications technologies?

- What, if any, are the barriers inhibiting older Australians uptake of information and communications technologies?

\section{Methodology}

The research aimed to collect data about general technology use by older Australians. The items on the survey were constructed around scales from surveys used for both Technology Acceptance Models (TAM) and User Information Satisfaction models (UIS) ${ }^{24,25,26}$. Both these groups of models have been used extensively and are accepted within the IT discipline as surrogate measures of the success and uptake of ICT across a variety of system types. Although significantly modified to address usage by older Australians, the adoption and modification of existing, tested scales made sense for this project and provided the researchers with an option to expand the study to other groups for comparative assessments to be made in the future.

The questions included in the survey to measure usage $^{24,25,26}$ were:

- "How many hours each week do you spend...."

o Surfing the internet, e.g. reading news and information

o Using a social networking site, e.g. Facebook, mySpace

o Creating, reading, sending instant messages, e.g. Skype or MS Messenger

o Creating, sending, receiving email

o Downloading music or videos

o Online shopping e.g. eBay

o Online banking o Online investment

o Studying

o Playing games/consoles

- "How many hours per week do you spend on each of the following?"

o Creating /editing word documents, e.g. MSWord

o Creating/editing or working with spreadsheets, e.g. MSExcel

o Creating/editing presentations, e.g. MSPowerPoint

o Creating/editing graphics, e.g. Adobe Photoshop

o Creating/editing video, e.g. Adobe Premiere

o Creating/editing music, e.g. Adobe Audition

o Creating/editing web pages,e.g. Dreamweaver

The scale descriptors for these questions were:

- $\quad<1 \mathrm{hr}$

- $1-10 \mathrm{hrs}$

- 11-20hrs

- $\quad>20 \mathrm{hrs}$

- N/A

The questions included in the survey to measure skill level ${ }^{25,26}$ were:

- "How would you rate your skill level in relation to each of the following computer technologies?"

o Word processing

o Spreadsheets

o Presentation software

o Graphics

o Audio

o Video

o Web page creation

o Using a computer

o Computer security

o Online Social networking

The scale descriptors respondents could choose from for each of the technologies were:

- Very Unskilled

- Unskilled

- Average

- Skilled

- Very Skilled

For comparative purposes the following question about respondent's skills relative to their colleagues ${ }^{26}$ was also included:

- How would you rate your IT skills compared to other residents? 
The scale descriptors respondents could choose from to answer this question were:

- Much Less Skilled

- Less Skilled

- About the Same

- More Skilled

- Much More Skilled

There were 92 useable responses to the survey received from the residents of Marian Grove Retirement Village. The retirement village is located in Sawtell on the Mid North Coast of New S outh Wales, Australia. The survey was conducted in January 2013 during the roll-out of the NB in the Coffs Harbour region. It should however be noted that at that point the NBN was not yet available at the Village although it $\mathrm{w}$ as expected infrastructure installation would commence sometime in mid-2013.

\section{Discussion of Survey Results}

It was intended that the researchers would undertake descriptive analysis of resp onses and analysis of the relationships among the variables. Correlation analysis was to be used for the initial examination of associations between the variables followed by regression modelling if warranted and appropriate relationships were evident from the correlations.

The correlation analysis was undertaken in 3 separate stages as follows:

- Correlations among the scales measuring time spent using PC applications

- Inter-item correlations among scales measuring time spent using PC applications and self-assessed skill level using web/PC applications

- Correlations among the scales measuring selfassessed skill level using web/PC applications

The descriptive analysis of the items is also included with the discussion of the correlations. This is done so that the reader gains a full understanding of the responses for each of the key variable groupings. The lack of correlations and small number of paired observations in some instances means further analysis of the relationships was not possible. This mea nt no regression modelling was undertaken.

\subsection{Correlations - time spent on PC applications and self-assessed skill levels}

The inter-item correlations among the scales measuring the hours that individuals spend on various PC applications did not show any significant relationships worth further comment. The main reason was the small number of paired observations. There was only 1 pair of observations that more than 10 ins tances with most having less than 5 . What is evident from the very small number of instances from the correlation analysis of these items is the low level of usage of PC applications by residents of the retirement village surveyed in this study. That the largest number of paired observations from this correlation analysis is $11(12.1 \%, \underline{\mathrm{n}}=91)$ and the lowest is $3(3.3 \%)$ shows that there were very small numbers of residents spending time using multiple applications. The table of correlations among these items has not been included in the paper given that there are no significant relationships among them.

There were significant correlations among the items measuring respondent's self-assessed skill levels using various web/PC technologies. These correlations are shown in Appendix 1, Table 1. The correlations among these items show that respondents thought that their skill level using web and PC applications was the same across different applications. It needs to be noted that these are correlations which means that those who thought their skills were good generally did so across a range of applications, but those who thought their skills were poor thought they were poor across the range of applications.

Correlations were run between the items measuring time spent on various PC applications and respondents self-assessed skill level using a variety of web/PC technologies Once again, there were a very small number of significant correlations but the number of cases was 4 or less, show ing again the low level of usage and engagement with computer applications by this group of respondents.

\subsection{Response Distributions - computer use}

The descriptive statistics showed that just over half of the respondents $(50.6 \%)$ used a computer, only $48.0 \%$ used the internet, and $51.0 \%$ used email (it is believed that the disparity in these figures is due to some respondents not recognising that email requires the internet). By contrast the Household Use of Information Technology Survey $2010-11^{4}$ shows that $83 \%$ of Australian households had access to a computer at home. Furthermore $77 \%$ of households with the internet were using it every day while a further $20 \%$ were using it weekly. The low engagement with online activities 
evident among respondents from Marian Grove is therefore noteworthy.

Those respondents who do however spend time online do so across a si milar spectrum of applications and tasks as do other Australians. A total of 13.3 million people across Australia reported accessing the internet at home with the most popular activities being: emailing (91\%); research, news and general browsing (87\%) and paying bills online and banking $(64 \%)^{4}$. The most common online activities among respondents were "surfing the internet" (70\% of respondents spent between 1-20 hours per week), email (53-1\% spent between 1-20 hours per week) and playing games (47.6\% spent between 1-20 hours per week).

\subsection{Response Distributions - skill levels}

Response distributions for self-assessed skill level in using various PC and web technologies are shown in The reason for this difference is not clear from this data but is an area that would be in teresting to examine further. It could simply be that a self-evaluation against a baseline (other residents) makes it easier or more precise for respondents to self-evaluate their level of skill. This could also explain why $25.6 \%$ thought they were more skilled than other residents but on ly $9.8 \%$ thought they were 'skilled' or 'more skilled' in using a computer. Reponses to the latter question could be compared to the broader population not just residents, and support a supposition that the younger generations are more skilled at using computers.
Figure 1. In all but one area of computer use the majority of respondents rated themselves as 'very unskilled'. The exception was the item asking respondents to rate their skill level 'using a computer'. The majority of respondents to this item indicated they were 'average'. Thus the majority of people in this group see themselves as being generally unskilled in the use of computer technologies and that that this low level of skill is typical of people in this retirement village.

Responses to the question 'How would you rate your IT skills compared to other residents? showed that $41.2 \%$ thought they were 'unskilled' or 'very unskilled' in the use of computers and $41.9 \%$ thought they were 'less skilled' or 'much less skilled' in the use of IT compared to other residents. However, $49 \%$ of respondents rated their skill level using a computer as 'average' whereas only $32.6 \%$ rated their skill level compared to other residents as 'about the same'.

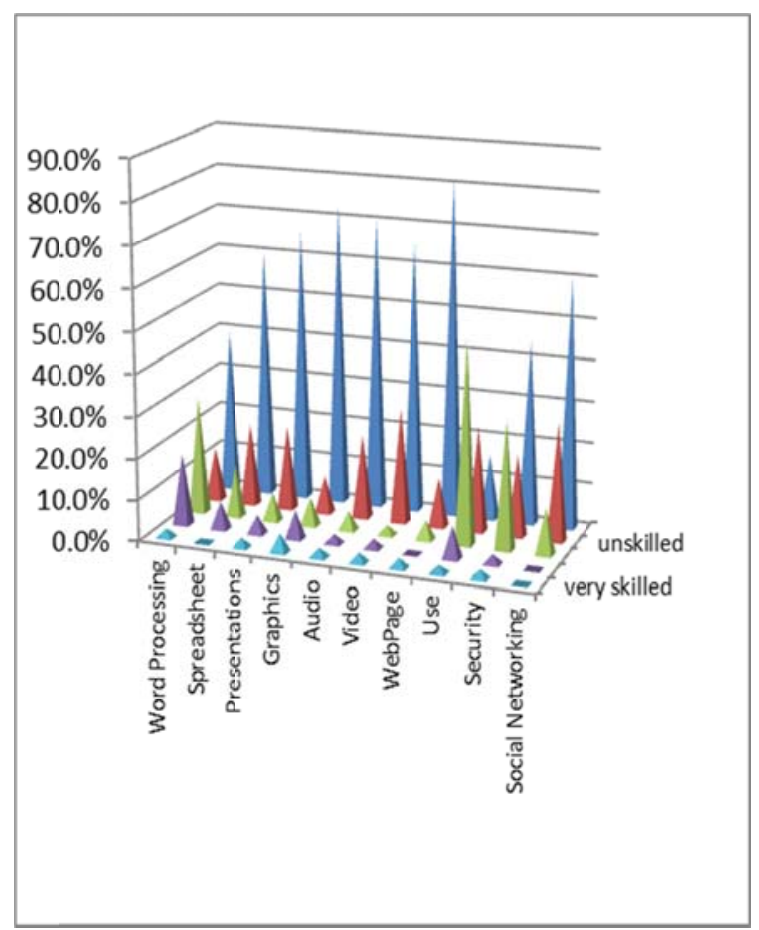

Fig. 1. Response distributions-self assessed skill level 


\subsection{Correlations - concerns with communications technologies and computers}

The researchers were also seeking to identify concerns that could affect older Australians use and uptake of computers. Correlations among these items are shown in Appendix 1, Table 2.

The correlations among a number of the items are over 0.8 indicating the items could be considered to be collinear. The items where most collinearity was evident was among those measuring unauthorised access (hacking, identity theft, viruses, etc) indicating that older Australians who are concerned about theft and unauthorised access to information about them that is held electronically, are concerned across a whole range of ICT threats from theft of personal data, illegal access and intentional destruction of information (viruses, etc...).

\subsection{Descriptive Analysis - concerns with communications technologies and computers}

The questions in this section of the survey covered 3 broad areas of concerns - unauthorised access to or theft of information, skills and benefits of computers, and concerns with the internet. The response distributions to each of these 3 groups of questions are shown below in the following 3 graphs.

The distribution of responses to questions about concerns with invasion of privacy is shown in Figure 2. The responses show that people were least concerned about the theft of medical information $(57.1 \%$ slightly concerned or not concerned at all) and were most concerned about the theft of financial information (46.0\% very concerned or extremely concerned).

Residents at the $\mathrm{r}$ etirement home were less concerned with issues associated with their knowledge of computers and the availability of support (see Figure 3 ). Over $60 \%$ or respondents were either 'slightly concerned' or 'not concerned at all'. However, nearly $25 \%$ of $\mathrm{r}$ espondents were 'quite concerned' or 'extremely concerned' about not knowing the benefits of computer use.

This may be an indication of the need to focus training and/or information sessions towards retirees that addresses benefits from information technology.

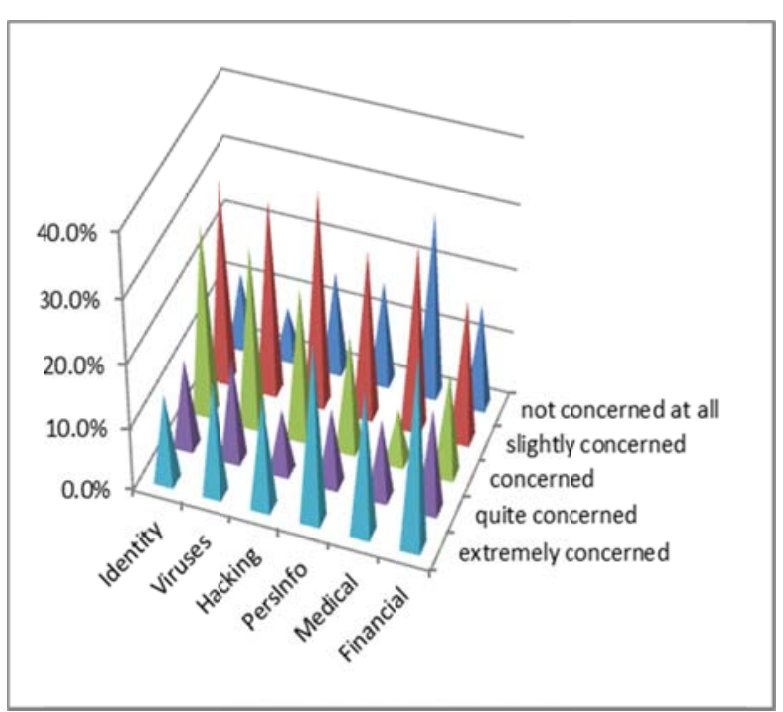

Fig. 2. Concerns-identity \& personal information

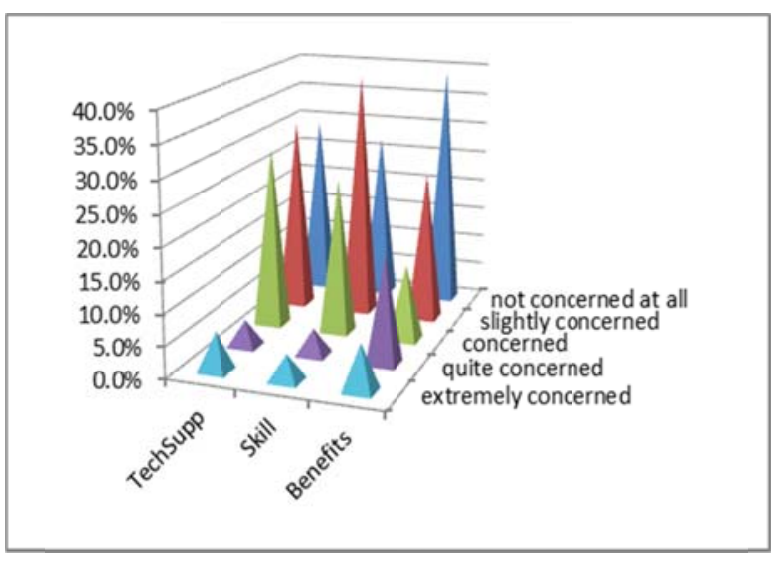

Fig. 3. Concerns - skills \& benefits of computers

Figure 4 shows concerns related to the internet. Respondents were not concerned with internet speed (almost $70 \%$ slightly concerned or not concerned at all) but just under $61 \%$ had concerns about the cost of broadband (28.3\% extremely concerned, $13.0 \%$ quite concerned and $19.6 \%$ concerned). 


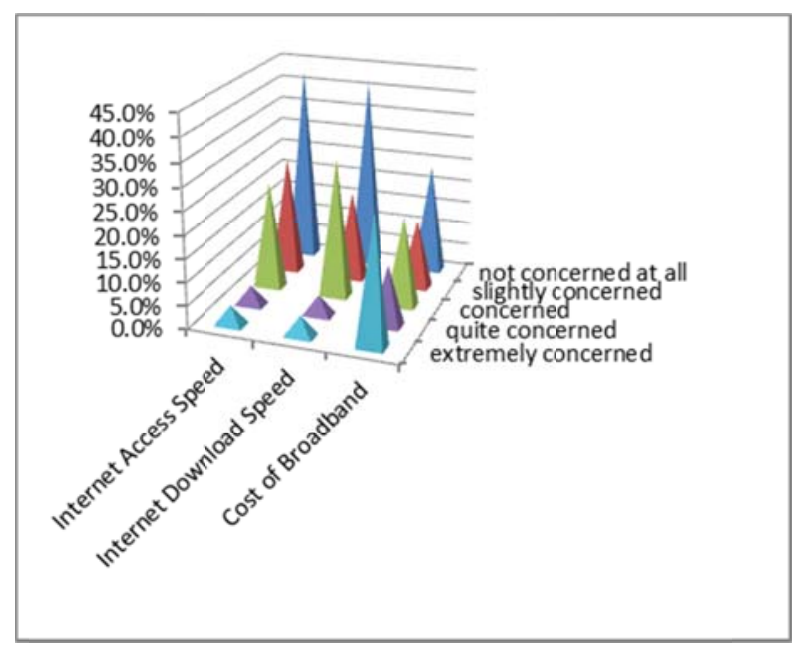

Fig. 4. Concerns related to the Internet

The lack of concern about internet speed is understandable given the marketing of the National Broadband Network (NBN) and the speeds that are expected. While many of the respondents indicated they hadn't used the internet it is understandable that they also would not be concerned about internet speed given Coffs Harbour is one of the early sites for rollout of the NBN and a $s$ a consequence has been the focus of considerable marketing and information about the benefits of high-speed broadband. This w ould presumably lead to an expectation that speed will not be an issue in the near future.

The fact that 'cost' is a concern is an issue that could be addressed by policy makers and the NBN Company. Although no data was collected related to respondents income, it is believed that many of the respondents would be g overnment pensioners and a smaller proportion would be self-funded retirees and that personal budgeting is important and therefore concerns about unknown costs becomes very relevant to this group.

\section{Conclusion}

While the authors acknowledge the small sample size, if these characteristics are typical of residents of retirement homes then there is a case to be made for involvement with this group of people to develop appropriate computer skills. The researchers intend to administer the survey more broadly to check if these issues are reflected among residents of other retirement facilities. It also needs to be acknowledged at this point that the retirement facility that was surveyed is in a coastal, regional location on the Mid North Coast of NSW with a 1 ocal government population of jus $t$ over 60,000 people. It is also a popular tourist destination subject to the general economic fluctuations associated with this type of location.

Therefore extrapolating the results more generally to the broader population of nursing home residents needs to be done with knowledge of the limitations and the understanding that the findings and resultant recommendations may be atypical.

The primary issue identified from the survey was the low level of usage of ICT among this group of residents. If this is ref lective of $t$ he broader population of retirement home residents then there is considerable scope for improving uptake. The benefits of the internet for enabling social inclusion, overcoming issues associated with accessing services by people with mobility issues, and general communications means it should be a valuable resource for this group.

The concern expressed by respondents about "cost of broadband access" is something that the researcher's feel could be addressed by provision of information related to the network replacing the copper based telecommunications network as well as internet systems and television systems such as Foxtel. Informal discussions with some residents indicate they were not aware that telephony systems, some healthcare facilities (e.g. MediAlert) and commercial television services will be delivered via the new infrastructure. What it does indicate is that despite the large expenditure on NBN advertising (A $\$ 11.226$ million in $2012^{32}$ and $\mathrm{A} \$ 14.032$ in $2013^{33}$ ), elderly Australians are not aware of the details of high-speed broadband being offered. Considerable information is available about proposed access costs but this is not accompanied by information about the services available through the internet and how access to these services is enhanced via high-speed broadband. For example, replacing telephone services, pay TV (with online, on-demand video), and gener al internet applications. Advertising the actual services 
that are available through the NBN rather than focusing on fast internet access would be considerably more meaningful to consumers.

It could be that the issues identified above are relevant to other groups within communities (e.g. within clusters of social and public housing), however further research would be required in order to test this hypothesis It i s important that social and broader community connectedness remain a ke y objective of retirement villages and they don't become separate enclaves within communities. If they do, this could lead to a reluctance by elderly people to enter aged care ${ }^{27}$. Information and communications technologies can assist partway in overcoming some of these issues but should not be mistaken as the sole panacea to increased inclusiveness for any group in society.

\section{References}

1. Baker C, "A Connection for All Ages: Enabling the benefits of High-Speed Internet Access for Older Adults",www.aarp.org/.../connection-for-all-ages-insightAARP-ppi-cons-prot.pd...

2. Australian Bureau of Statistics, 2011, Australian Social Trends March 2011, cat no. 4102.0, viewed 21 December 2011, www.abs.gov.au/AUSSTATS/abs@.nsf/Lookup/4102.0 Main+Features 10Mar+2011

3. Australian Bureau of Statistics, 2012, Internet Activity, Australia, December 2012, cat no. 8153, viewed 23 May 2013,

http://www.abs.gov.au/ausstats/abs@.nsf/Latestproducts/ 8153.0Media\%20Release1December\%20 $2012 \quad$ ? opendocument $\&$ tabname $=$ Summary $\&$ prodno $=8153.0 \&$ is sue $=$ December\%202012\&num $=\&$ view $=$

4. Australian Bureau of Statistics, 2011, Household Use of Information Technology, Australia, 2010-11, cat no . 8146.0, viewed 21 December 2011, www.abs.gov.au/ausstats/abs@.nsf/Latestproducts/01B5 AC65512 C0960CA25796600152D04?opendocument

5. Australian Bureau of Statistics, 2008, Population Projections Australia, 2006 to 2101, cat n o. 3222.0, viewed $29 \quad$ November 2011, www.abs.gov.au/ausstats/abs@.nsf/mf/3222.0

6. Australian Bureau of Statistics, 2011, Population by Age and Sex, Regions of Australia, 2011, cat no. 3235, viewed 11April 2013 http://www.abs.gov.au/ausstats/abs@.nsf/Products/3235. 0 2011 Main+Features Main+ Features?OpenDocument

7. Australian Bureau of Statistics, 2012, Population by Age and Sex, Regions of Australia, 2012, cat no. 3235.0, viewed 4 Nov 2013,
http://www.abs.gov.au/ausstats/abs@.nsf/Products/3235. 0 2012 Main+Features $\sim$ Main+Features?OpenDocument \#PARALINK2

8. Hogeboom, D, Mc Dermott, R, Perrin, K \& Os man, H 2010, 'Internet use and Social Networking Among Middle Aged and Older Adults', Educational Gerontology, vol. 36, no. 2, pp. 93-111, Psychological and Behavioural Sciences Collection, EBSCO host, viewed 29 January 2013.

9. Nayak, L. U., S., Priest, L., \& W hite, A. P. 2010`An application of the techn ology acceptance model to the level of internet usage by older adults' Universal Access in the Information Society, vol. 9, no.4, pp. 367-374. doi:http://dx.doi.org/10.1007/s10209-009-0178-8, viewed 23 May 2013.

10. Zickuhr, Kathryn, \& Madden, Mary 2012, Older Adults and Internet Use. PEW Internet \& American Life Project, June 6, 2012, http://pewinternet.org/Reports/2012/Olderadults-and-internet-use.aspx, accessed on $17^{\text {th }}$ January 2013.

11. Jung, Y, Peng, W, Moran, M, Jin, S, McLaughlin, M, Cody, M, Jordan-Marsh, M, Albright, J \& Silverstein, M 2010, 'Low-Income Minority Seniors' Enrollment in a Cybercafe: Psychological Barriers to Crossing the Digital Divide', Educational Gerontology, vol. 36, no. 3, pp. 193-212, Psychology and Behavioral Sciences Collection, EBSCOhost, viewed 29 January 2013.

12. Hough, M, Kobylanski, A 2009, 'Increasing elder consumer interactions with information technology', Journal of Consumer Marketing, vol. 26, no.1, pp.39-48, viewed 21 December 2011, Emerald Insight database.

13. Cresci, M, Yaran di, H \& Morrell, R 2010, 'Pro-Nets Versus No-Nets: Differences in Urban Older Adults' Predilections for Internet Use', Educational Gerontology, vol. 36, no. 6, pp. 500-520, Psychology and Behavioral Sciences Collection, EBSCOhost, viewed 29 January 2013.

14. McMurtrey, M, Downey, J, Zeltmann, S \&McGaughey, R 2011, 'Seniors and Technology: Results from a Field Study', The Journal of Computer Information Systems, vol.51, no. 4, pp. 22-30, viewed 21 December 2011, ABI Inform Global database.

15. Broady, T, Chan, A, \&Caputi, P 2010, 'Comparison of older and younger adults' attitudes towards and abilities with computers: Implications for training and learnin g', British Journal Of Educational Technology, vol. 41, no. 3, pp. 473-485, Academic Search Premier, EBSCOhost, viewed 29 January 2013.

16. Olson, K, O'Brien, M, Rogers, W \&Charness, N 2011, 'Diffusion of Technology: Frequency of use for Younger and Older Adults', Ageing International, vol. 36, no. 1 pp.123-145, viewed November 29 2011, Proquest 5000 database.

17. Passyn, K, Diriker, M \& Set tle, R 201 1, 'Images of Online Versus Store Shopping: Have the attitudes of men and women, young and old really changed?', Journal of Business and Economics Research, Vol. 9, no. 1, pp.99- 
110, viewed 21 Decem ber 2011, ABI Inform Global database.

18. Kwon, W \& No h, M, 2010, 'The influence of prior experience and age on mature consumers' perceptions and intentions of internet apparel shopping', Journal of Fashion Marketing and Management, vol. 14, no. 3, pp. 335-349, viewed $22^{\text {nd }}$ October 2012, Emerald Insight database.

19. Weaver McCloskey, DW 2006 ' The importance of ease of use, usefulness, and trust to online consumers: An examination of the technology acceptance model with older consumers' Journal of Organizational and End User Computing, vol. 18, no. 3, 47-65. Retrieved from $\mathrm{http}: / /$ ezproxy.scu.edu.au/login?url=http:// search. proquest .com/ docview/199877015?accountid=16926, viewed 23 May 2013.

20. Mitzner, T, Boron, J, Fausset, C, Adams, A, Charness, N, Czaja, S, Dijkstra, K, Fisk A, Rogers, W \&Sharit, J 2010, 'Older adults talk technology: Technology usage and attitudes', Computers in Hu man Behaviour, vol.26, pp. 1710-1721, viewed 21 December 2011, Proquest 5000 database.

21. Chang J, S amuel N 20 04, 'Internet shopper Demographics and Buying Behaviour in Australia', Journal of American Academy of Business, Cambridge, Sept 2004; 5,1/2; pp. 171-176, viewed 20 December 2011, ABI/Inform Global database.

22. Burns, P, Jones, C, Iverson, D \& Caputi, P, 2012,' Riding the wave or padd ling in the shallows? Understanding older Australians' use of the internet', Health Promotion Journal of Australia, vol. 23, issue 2, pp. 145-8, viewed $23^{\text {rd }}$ October 2012, Proquest 5000 database.

23. Sum, S, Mathews, M \&Huges, I, 2009,' Participation of older adults in cyberspace: How Australian older adults use the internet', Australasian Journal on Ageing, vol. 28 , no. 4 , pp. $189-193$, viewed $29^{\text {th }}$ October 2012, Wiley Online Library.

24. Chutter MY, 2009, 'Overview of the Technology Acceptance Model: Origins, Developments and Future Directions', Indiana University, USA. Sprouts: Working Papers on Information Systems, 9(37). http://sprouts.aisnet.org/9-37.

25. Ives, B., Olson, M.H., Baroudi, J.J. 1983, 'The Measurement of User Information Satisfaction',Communications of the ACM, vol. 27, no. 10 , pp. $785-793$.

26. Xiao, L, Dasgupta, S 2002, 'Measurement of User Satisfaction with web-Based Information Systems: An Empirical Study', Eighth Americas Conference on Information Systems, http://melody.syr.edu /hci/ amcis02_minitrack/CR/Xiao.pdf, Syracuse University: New York.

27. Judd, B. 2011, 'Enclave or engage? Mixity and housing choices in an agei ng society', Enhr Conference 2011
http://www.enhr2011.com/sites/default/files/PaperJudd\%20Final_WS15.pdf

28. Australian Communications and Media Authority, 2013, Communications report 2011-12 series, Report 3Smartphones and tablets, Take-up and use in Australia, http://www.acma.gov.au/scripts/nc.dll?WEB $/ \mathrm{STANDARD} / 1001 / \mathrm{pc}=\mathrm{PC} 600063$

29. Hutchinson, J. 2012, 'Government to spend $\$ 20 \mathrm{~m}$ on NBN ads', Financial Review, 23 ${ }^{\text {rd }}$ October, 2012, http://www.afr.com/p/technology/government_to_spend_ on_nbn_ads_pubnnL08CZhoPJ0mC3H8KP

30. Oxford Dictionary, viewed 13 December 2011, $<\mathrm{http}$ ://www.oxforddictionaries.com $>$.

31. McMurtrey, M, Downey, J, Zeltmann, S \& McGaughey, R 2011, 'Seniors and Technology: Results from a Field Study', The Journal of Computer Information Systems, vol.51, no. 4, pp. 22-30, viewed 21 December 2011, ABI Inform Global database.

32. NBN Co, 2012, NBN Co Annual Report 2011-2012, http://www.google.com.au/url?sa $=t \& r c t=j \& q=\& e s r c=s \&$ source $=$ web\&cd $=6 \&$ ved $=0$ CGYQFjAF \&url $=$ http $\% 3 \mathrm{~A} \%$ 2F\%2Fwww.nbnco.com.au $\% 2 \mathrm{Fcontent} \% 2 \mathrm{Fdam} \% 2 \mathrm{Fnbn}$ co $\% 2$ Fdocuments $\% 2$ Fnbn-co-annual-report2013.pdf\&ei=dcwnU7OGO46okgXju4CgAQ\&usg=AFQ iCNGjOj vplyNOlUIUb3xaPmRpLNyVg\&sig2=vJrtfzxa UjthBBQWs5goAA, viewed 18 March 2014.

33. NBN Co, 2012, NBN Co Annual Report 2012-2013, http://www.google.com.au/url?sa=t\&rct=i\&q $=\&$ esrc $=\mathrm{s} \&$ source $=$ web\&cd $=5 \&$ ved $=0 \mathrm{CF} 0 \mathrm{QFjAE} \&$ url $=\mathrm{http} \% 3 \mathrm{~A} \% 2$ F\%2Fwww.nbnco.com.au\%2Fassets\%2Fdocuments\%2F nbnco-annual-report2012.pdf\&ei=dcwnU7OGO46okgXju4CgAQ\&usg=AFQ jCNH93flfB5VMvJV9WAroiwopr86g\&sig2=Mhu5VeKAYYMSY3pSt0RqEA, viewed 18 March 2014. 


\section{APPENDIX 1}

Table 1: Skill level with computer technology

\begin{tabular}{|c|c|c|c|c|c|c|c|c|}
\hline & Spreadsheet & Presentations & Graphics & Audio & Video & WebPage & Use & Security \\
\hline Word & $.653^{* *}$ & $.669^{* *}$ & $.604^{* *}$ & $.461^{* *}$ & $.401^{* *}$ & $.368^{*}$ & $.725^{* *}$ & $.462^{* * *}$ \\
\hline Processsing & 43 & 42 & 42 & 41 & 41 & 40 & 46 & 43 \\
\hline \multirow[t]{2}{*}{ Spreadsheet } & & $.592^{* *}$ & $.586^{* *}$ & $.703^{* *}$ & $.612^{* *}$ & $.514^{* *}$ & $.567^{* *}$ & $.498^{* *}$ \\
\hline & & 43 & 43 & 43 & 43 & 42 & 45 & 44 \\
\hline \multirow[t]{2}{*}{ Presentations } & & & $.856^{* *}$ & $.653^{* *}$ & $.557^{* * *}$ & $.511^{* *}$ & $.645^{* *}$ & $.476^{* *}$ \\
\hline & & & 43 & 42 & 42 & 41 & 44 & 43 \\
\hline \multirow[t]{2}{*}{ Graphics } & & & & $.859^{* *}$ & $.753^{* *}$ & $.835^{* *}$ & $.605^{* *}$ & $.376^{*}$ \\
\hline & & & & 43 & 43 & 42 & 44 & 43 \\
\hline \multirow[t]{2}{*}{ Audio } & & & & & $.890^{* *}$ & $.883^{* *}$ & $.475^{* *}$ & $.351^{*}$ \\
\hline & & & & & 43 & 42 & 44 & 42 \\
\hline \multirow[t]{2}{*}{ Video } & & & & & & $.827^{* *}$ & $.471^{* *}$ & .282 \\
\hline & & & & & & 42 & 43 & 42 \\
\hline \multirow[t]{2}{*}{ Web Pages } & & & & & & & $.435^{* *}$ & .237 \\
\hline & & & & & & & 42 & 42 \\
\hline \multirow[t]{2}{*}{ Use } & & & & & & & & $649^{* * *}$ \\
\hline & & & & & & & & 45 \\
\hline
\end{tabular}

Table 2. Concerns with information technology

\begin{tabular}{|c|c|c|c|c|c|c|c|}
\hline $\begin{array}{l}\text { Viruses/ Worms/ } \\
\text { Trojan Horses }\end{array}$ & Hacking & $\begin{array}{l}\text { Unauthorised } \\
\text { Access } \\
\text { Personal } \\
\text { Information }\end{array}$ & to & $\begin{array}{l}\text { Unauthorised } \\
\text { Access to Medical } \\
\text { Information }\end{array}$ & $\begin{array}{l}\text { Unauthorised } \\
\text { Access } \\
\text { Financial } \\
\text { Information }\end{array}$ & to & $\begin{array}{l}\text { Lack } \\
\text { Technical } \\
\text { Support }\end{array}$ \\
\hline $.842^{* *}$ & $.900^{* * *}$ & $.875^{* * *}$ & & $.748^{* *}$ & $.831^{* *}$ & & $.540^{* *}$ \\
\hline \multirow[t]{11}{*}{50} & 51 & 50 & & 49 & 50 & & 48 \\
\hline & $.858^{* *}$ & $.770^{* * *}$ & & $.720^{* *}$ & $.669^{* *}$ & & $.497^{* *}$ \\
\hline & 50 & 49 & & 48 & 49 & & 47 \\
\hline & & $.878^{* *}$ & & $.688^{* *}$ & $.790^{* *}$ & & $.580^{* *}$ \\
\hline & & 50 & & 49 & 50 & & 48 \\
\hline & & & & $.795^{* *}$ & $.901^{* *}$ & & $.409^{* *}$ \\
\hline & 49 & & & & 50 & & 47 \\
\hline & & & & & $.783^{* *}$ & & $.407^{* *}$ \\
\hline & & & & & 49 & & 47 \\
\hline & & & & & & & $.444^{* *}$ \\
\hline & & & & & & & 47 \\
\hline
\end{tabular}

